УДК 332.1 JEL H76

Ланина Лилия Анатольевна

канд. экон. наук, ФГБОУ ВО «Всероссийский государственный институт кинематографии имени С. А. Герасимова», г. Москва

e-mail:lan_vgik@mail.ru

Малышев Антон Владимирович канд. экон. наук, ФГБОУ ВО «Всероссийский государственный институт кинематографии имени С. А. Герасимова», г. Москва e-mail: a.malyshev_vgik@mail.ru

\section{Lanina Liliya}

Candidate of Economic Sciences, the ALL-Russian state Institute of Cinematography named

after S. A. Gerasimov

e-mail:lan_vgik@mail.ru

\section{Malyshev Anton}

Candidate of Economic Sciences, the ALL-Russian state Institute of Cinematography named after S. A. Gerasimov

e-mail: a.malyshev_vgik@mail.ru
DOI 10.26425/1816-4277-2019-4-75-82

\section{ЦЕЛЕВЫЕ СУБСИДИИ КАК ИНСТРУМЕНТ РАЗВИТИЯ КИНОПОКАЗА В РЕГИОНАХ РОССИИ}

Аннотация. Осуществление протекционистских мероприятий со стороны государства в области кинопоказа является значимым для всей киноиндустрии в иелом, так как состояние российского кинопоказа влияет и на дистрибьюизию, и на кинопроизводство. В статье исследован процесс реализаиии государственной программы по предоставлению субсидий на модернизачию кинотеатров в мальх и средних городах России. Проанализированы текущие результаты программы, их значимость для регионального кинопоказа и для российской киноиндустрии. Выделены особые сочиально-экономические условия функционирования субсидируемых кинотеатров. Предложена организация двухуровневой системы дальнейшей поддержки деятельности субсидированных кинотеатров и рассмотрен комплекс мероприятий по достижению иелей государственной программы на длительный период.

Ключевые слова: киноиндустрия, кинопоказ, государственная субсидия, Фонд кино, регион.

\section{TARGET SUBSIDIES AS A FILM SCREENING DEVELOPMENT TOOL IN RUSSIAN REGIONS}

\begin{abstract}
Execution of protectionist measures by the state in the film screening field is a significant for the entire film industry as a whole, as the state of the Russian film screening affects both distribution and film production. The implementation process of the state program to provide subsidies for the cinemas modernization cinemas in small and medium-sized Russia cities has been examined. The current program results, their importance for the regional film screening and the Russian film industry have been analyzed. The special socio-economic conditions of the subsidized theaters functioning have been highlighted. The two-level system organization for further activities subsidized cinemas support is proposed and a measures set to achieve the state program goals for the long term have been offered.
\end{abstract}

Keywords: film industry, film screening, state subsidy, Cinema Foundation of Russia, region.

Организации кинопоказа представляют собой базовую составляющую киноиндустрии, так как являются посредником между производителями фильмов и зрителями. Одновременно с этим, состояние рынка кинотеатрального показа влияет на экономическую эффективность кинодистрибьюции и кинопроизводства. Именно поэтому осуществление протекционистских мероприятий со стороны государства в области кинопоказа является значимым для всей киноиндустрии в целом.

На протяжении длительного периода положительная динамика посещений кинозалов и, соответственно, доходов кинопоказа в России обеспечивалась путем открытия новых кинозалов за счет частного капитала и, в основном, в крупных городах [12].

В 2014-2015 гг. произошло замедление роста рынка кинопоказа (за первые 6 месяцев 2015 г. прирост коммерческих кинозалов в России составил всего лишь 1,5 \%) [3].

Одновременно снизился и уровень кинопотребления. В 2014 г. в России уровень кинопотребления на душу населения в целом по стране составлял 1,21 раза в год (в городах с кинопоказом - 2,03 раза в год). По итогам 2015 г. статистика кинопотребления показала снижение этих показателей: 1,19 и 1,96 соответственно [2].

(C Ланина Л.А., Малышев А.В., 2019. Статья доступна по лицензии Creative Commons «Attribution» («Атрибуция») 4.0. всемирная (http://creativecommons.org/licenses/by/4.0/).

The Author(s), 2019. This is an open access article under the CC BY 4.0 license (http://creativecommons.org/licenses/by/4.0/). 
Отрицательный тренд проявился и в отношении интереса к российскому кино: так доля российских фильмов по количеству посещений в кинопоказе в 2015 г. составила 17,6 \%, в то время как в 2014 г. этот показатель был на уровне 18,7 \%.

Одновременно с этим, по состоянию на 2015 г. в городах с населением менее 100 тыс. человек практически отсутствовали кинозалы, оснащенные современным оборудованием для кинопросмотра. При этом:

- среди городов с численностью населения от 50 до 100 тыс. человек - только 80 \% имели от одного и более кинотеатра;

- среди городов с численностью населения менее 50 тыс. человек - только $25 \%$ имели от одного и более кинотеатра [2].

Эта диспропорция обусловлена тем, что в небольших населенных пунктах организации кинопоказа функционируют в условиях целого ряда проблем и без целенаправленной государственной поддержки кинопоказ появиться не может.

С декабря 2015 г. Министерством культуры Российской Федерации (далее - РФ) и Фондом социальной и экономической поддержки отечественной кинематографии (далее - Фонд кино) была запущена государственная программа субсидирования кинофикации малых и средних городов России.

К основным целям программы следует отнести:

- развитие кинопоказа в регионах России;

- повышение доступности современного кинопоказа;

- увеличение доли российского кино в прокате.

Процесс отбора участников программы, выделение средств и контроль их целевого использования был возложен на Фонд кино.

Программа предоставления бюджетной субсидии организации кинопоказа предусматривает следующие условия:

- выделение субсидии в размере до 5 млн руб. на один кинозал на безвозвратной основе;

- средства выделяются целевым образом на приобретение, транспортировку и установку оборудования для кинозалов (экран, проекторы, кресла и т. д.);

- кинотеатр берет обязательства в течение трех лет не менее половины сеансов ежеквартально выделять российскому кино;

- кинотеатр предоставляет сведения о показах фильмов в кинозалах через единую федеральную автоматизированную информационную систему (далее - ЕАИС).

За период с декабря 2015 г. по декабрь 2018 г. Фондом кино было проведено пять конкурсов по предоставлению средств на кинофикацию малых и средних городов России. И если первые два конкурса предполагали выделение субсидий для населенных пунктов с численностью населения до 100 тыс. человек, то уже с 3-го конкурса программа была расширена до населенных пунктов с численность до 500 тыс. жителей.

По результатам 1-го конкурса были удовлетворены заявки из 51 субъекта РФ, а к концу 2016 г. в конкурсе участвовали организации кинопоказа из 64 субъектов РФ. Всего же в программе субсидирования приняли участие кинотеатры из 81 субъекта РФ.

За время проведения конкурсов было подано более 3,5 тыс. заявок, отобрано и поддержано 811 кинозалов, распределено более 4 млрд рублей [16].

Таблий 1

Показатели реализации государственной программы по кинофикации малых и средних городов России за период 2015-2018 гг.

\begin{tabular}{|c|c|c|}
\hline $\begin{array}{c}\text { Дата проведения } \\
\text { конкурса }\end{array}$ & $\begin{array}{c}\text { Общая сумма } \\
\text { поддержки, руб. }\end{array}$ & Получатели средств \\
\hline декабрь, 2015 г. & 705 млн & 143 кинозалов в 125 населенных пунктах России \\
июнь, 2016 г. & 766,7 млн & 155 кинозалов в 148 населенных пунктах России \\
декабрь, 2016 г. & 739 млн & 139 кинозалов в 127 населенных пунктах России \\
\hline
\end{tabular}


Окончание табл. 1

\begin{tabular}{|c|c|c|}
\hline $\begin{array}{c}\text { Дата проведения } \\
\text { конкурса }\end{array}$ & $\begin{array}{c}\text { Общая сумма } \\
\text { поддержки, руб. }\end{array}$ & Получатели средств \\
\hline ноябрь, 2017 г. & 1 млрд & 202 кинозала в 171 населенных пунктах России \\
март, 2018 г. & 1 млрд & 172 кинозалам в 155 населенных пунктах России \\
\hline
\end{tabular}

Источник: $[4 ; 5 ; 6 ; 7 ; 8]$

Первые результаты реализации программы за период с 01.07.2016 г. по 01.07.2017 г. показали рост киносети на 4,5 \% (от общего роста киносети России - на 11,3 \%) по сравнению с аналогичным предыдущим периодом.

На начало 2018 г. по данной программе было уже обновлено 422 кинозала в 69 регионах России. К концу 2018 г. число кинозалов, открытых по программе, должно по плану составить 790 кинозалов.

Преобладающее количество удовлетворенных заявок на получение субсидии пришлось на кинозалы в муниципальных клубных учреждениях культуры:

- по итогам 1-го конкурса: предоставлены субсидии 109 муниципальным домам культуры;

- по итогам 2-го конкурса: предоставлены субсидии 140 муниципальным домам культуры;

- по итогам 2-го конкурса: предоставлены субсидии 115 муниципальным домам культуры;

- по итогам 2-го конкурса: предоставлены субсидии 155 муниципальным домам культуры;

- по итогам 5-го конкурса: предоставлены субсидии 145 муниципальным домам культуры.

Фонд кино, предоставляя субсидию, рассматривал в первую очередь значимость кинозала для населенного пункта, независимо от численности населения. Так, например, по результатам конкурсов в Ростовской области субсидии для модернизации были предоставлены 16-ти кинозалам, из них - 14-ти кинозалам в муниципальных клубных учреждениях культуры. В целом 333 тыс.человек в Ростовской области получили доступ к современному кинопоказу (табл. 2).

Таблица 2

\section{Получатели государственных субсидий по программе кинофикации в Ростовской области}

за период с 2015-2017 гг.

\begin{tabular}{|l|l|c|c|}
\hline Наименование организации - получателя средств & \multicolumn{1}{|c|}{$\begin{array}{c}\text { Наименование } \\
\text { населенного пункта }\end{array}$} & $\begin{array}{c}\text { Численность } \\
\text { населения, } \\
\text { тыс. чел. }\end{array}$ & $\begin{array}{c}\text { Выделенная } \\
\text { сумма, руб. }\end{array}$ \\
\hline МБУК «Городской Дворец культуры» & г. Гуково & 66,332 & 5000000 \\
МБУК «Районный Дворец культуры «Вешенский» & ст-ца Вешенская & 9,261 & 4998800 \\
МУ «Октябрьский районный Дворец культуры» & р-п Каменоломни & 10,514 & 5000000 \\
МБУК «Дом культуры» & п. Коксовый & 7,642 & 4989800 \\
ООО «Донресурс-1» & г. Красный Сулин & 38,567 & 4998700 \\
ООО «Донресурс-1» & г. Красный Сулин & 38,567 & 4998700 \\
МБУК «Районный Дом культуры Неклиновского района» & с. Покровское & 12,369 & 4993500 \\
МБУК «Районный Дом культуры» & р.п. Усть-Донецкий & 11,256 & 4802500 \\
МБУК «Цимлянский городской досуговый центр «Ком- & г. Цимлянск & 14,558 & 4998800 \\
сомолец» & г. Зверево & 19,456 & 5000000 \\
МУК Социально-культурный Центр «Маяк» & п. Зимовники & 18,070 & 4976000 \\
МУК «Социально-культурный центр «Сокол» & с. Песчанокопское & 10,593 & 4998000 \\
МБУК «Районный Дворец культуры «Юбилейный» & г. Сальск & 58,179 & 4998000 \\
МБУК «Районный Дворец культуры им. Р.В. Негре- & гец \\
\hline
\end{tabular}


Окончание табл. 2

\begin{tabular}{|l|l|c|c|}
\hline Наименование организации - получателя средств & \multicolumn{1}{|c|}{$\begin{array}{c}\text { Наименование } \\
\text { населенного пункта }\end{array}$} & $\begin{array}{c}\text { Численность } \\
\text { населения, } \\
\text { тыс. чел. }\end{array}$ & $\begin{array}{c}\text { Выделенная } \\
\text { сумма, руб. }\end{array}$ \\
\hline МБУК «Районный Дом культуры» & г. Семикаракорск & 22,118 & 4998000 \\
МБУК «Орловский районный Дом культуры» & п. Орловский & 18,757 & 5000000 \\
МБУК Мясниковского района «Районный Дом культуры» & с. Чалтырь & 15,334 & 4990000 \\
\hline
\end{tabular}

Источник: [4; 5; 6; 7; 8; 15]

С учетом того, что за рассматриваемый период бюджет Ростовской области был стабильно дотационным и в среднем дотационность составляла 8,4 \% (2015 г. - 8,1 \%, 2016 г. - 7 \%, 2017 г. - 10 \%), а также большую часть расходов областного бюджета составляют социальные расходы, такая целевая поддержка муниципальных организаций является существенной [14].

Эффективность реализации государственной программы субсидирования кинофикации, помимо увеличения количества площадок кинопоказа по стране, выражается и в показателях российского кинопоказа в целом. Вклад субсидированных кинотеатров в развитие киноиндустрии России в 2016 г. составил 0,6 \% посещений и 0,5 \% кассовых сборов от общего объема по стране; в первом полугодии 2017 г. - 2 \% посещений и 1,5 \% кассовых сборов от общего объема по стране [16].

Всего на начало 2018 г. в новых залах было проведено 582,5 тыс. сеансов с общим количеством зрителей порядка 5,5 млн человек, а объем общих кассовых сборов составил около 1 млрд рублей.

Одновременно увеличился и показатель российских фильмов в кинопоказе: если в 1 квартале 2016 г. он составлял 26,1% от общего числа фильмов, то в 1 квартале 2018 г. он составил 48,9 \% [16].

Соответственно, положительная динамика роста кинозалов повлияла и на бокс-офис российских фильмов в кинопоказе.

Таблица 3

Показатели российского кинопоказа за 2015-2018 гг.

\begin{tabular}{|l|c|c|c|c|}
\hline \multicolumn{1}{|c|}{ Показатель } & \multicolumn{1}{|c|}{$\mathbf{2 0 1 5}$ год } & $\mathbf{2 0 1 6}$ год & $\mathbf{2 0 1 7}$ год & $\mathbf{2 0 1 8}$ год \\
\hline $\begin{array}{l}\text { Совокупный бокс-офис отечественных } \\
\text { фильмов }\end{array}$ & 7,2 млрд руб. & 8,6 млрд руб. & 13,02 млрд руб. & 13,8 млрд руб. \\
$\begin{array}{l}\text { Совокупная посещаемость отечествен- } \\
\text { ных фильмов }\end{array}$ & 31,1 млн чел. & 35,2 млн чел. & 54,7 млн чел. & 57,9 млн чел. \\
\hline
\end{tabular}

Источник: [3; 16]

В то же время важно отметить, что кинопоказ в большинстве субсидированных кинотеатрах осуществляется в особых социально-экономических условиях в отличии от кинопоказа в крупных городах. Сюда следует отнести:

- ограниченные возможности по установлению стоимости билетов;

- преобладание среди населения лиц среднего и старшего возраста, гораздо менее активного по отношению к кинопросмотру, чем люди молодого возраста;

- невысокий уровень доходов населения и, соответственно, уровень доходов самого кинотеатра недостаточны для достижения окупаемости затрат;

- использование помещений кинотеатра для реализации социально-культурных мероприятий муниципальных органов власти.

Одновременно, происходит постепенное исчезновение традиций посещения кинотеатра, при том, что кинотеатр зачастую остается единственной площадкой организации досуга [10]. 
Кроме того, существует сильная временная зависимость киносеансов от востребованности кинопоказа (вечернее время, выходные дни).

Все вышеперечисленные факторы значительно влияют на доходность деятельности таких кинотеатров. На этом фоне отдельной проблемой для большинства субсидированных кинотеатров является прокатная плата, устанавливаемая дистрибьюторами на каждый фильм, предоставляемый кинотеатру для показа.

Прокатная плата взимается авансовым платежом и является минимальной гарантией для дистрибьютора по оплате его расходов на доставку контента, производство цифровых «ключей», печать и доставку полиграфии [9].

Большая часть российских дистрибьюторов не выделяет отдельно субсидированные кинозалы, предлагая стандартные условия сотрудничества. В результате высокая прокатная плата, особенно на премьерные фильмы, заставляет субсидированные кинотеатры отказываться от премьер на своих площадках и брать фильмы в прокат вторым экраном, т.е. через пару недель после начала кинопоказа по стране. В сложившейся бизнес-практике для фильмов вторым экраном дистрибьюторы либо значительно снижают прокатную плату либо могут не устанавливать ее вовсе. Но, как правило, вторым экраном дистрибьюторы стремятся предоставлять в показ иностранные картины, придерживая российские фильмы. Что идет вразрез с задачами кинотеатра по обязательствам кинопоказа объема российских фильмов в рамках полученной субсидии. Помимо этого, остро встает проблема кинопоказа у субсидированных кинотеатров в летний период. Дистрибьюторы стремятся сдвинуть премьеры российских фильмов на осенний период в условиях невысоких сборов летом, что также лишает субсидированные кинотеатры возможности выполнять требования по ежеквартальному объему российских фильмов в кинопоказе.

В целях становления, развития деятельности субсидированных кинотеатров, достижения эффективности в реализации целей программы субсидирования необходим комплекс мероприятий на основе двух уровней координации и взаимодействия всех субъектов, заинтересованных в развитии кинопоказа в регионах России.

На первом уровне целесообразно организационное взаимодействие Министерства культуры, Фонда кино с Ассоциацией кинодистрибьюторов по вопросам установления системы льгот для субсидированных кинотеатров (в первую очередь, по прокатной плате, летнему кинопоказу, приоритету российских фильмов в показе).

Представляется более рациональным именно решение вышеуказанных вопросов на уровне Ассоциации, созданной в конце 2017 г. крупнейшими дистрибьюторами России, деятельность которой направлена на разработку общих решений со всеми дистрибьюторами и кинопоказчиками.

Второй уровень - это создание региональных организационных структур по оказанию помощи и поддержки субсидированным кинотеатрам, в том числе в части координации их деятельности, разработки и реализации программ, направленных на формирование управленческой культуры.

Кинотеатральный бизнес напрямую зависит от посещаемости, которая, в свою очередь, связана с привлекательностью кинотеатра для зрителей и складывается из нескольких составляющих: качество услуг кинотеатра и кинопоказа, а также репертуарной политики (букинга).

Сравнительный анализ результатов Всероссийских опросов киноаудитории показал, что российский зритель взрослеет, численность молодежи в составе населения страны сокращается. Меняется мотивация для похода в кино, все больше зритель отзывается на нестандартные мероприятия на площадке кинотеатра [11].

Соответственно, для привлечения зрителей в кинозалы муниципальных клубных учреждений культуры сегодня необходим весь комплекс маркетинговых мероприятий, который уже доказал свою эффективность на практике в деятельности кинотеатров мегаполисов, в том числе:

- разработка ценовой политики с диверсифицированной скидочной системой;

- активное взаимодействие со зрителями с использованием сети Интернет, в том числе создание аккаунтов кинотеатра в социальных сетях;

- проведение различных промоакций, творческих встреч;

- организация образовательных программ в сотрудничестве с образовательными учреждениями;

- проведение различных мероприятий креативного характера (ретроспективы фильмов, показы фильмов кинофестивалей, «Ночи кино» и др.).

Успешность деятельности муниципальных клубных учреждений культуры напрямую связана со взаимодействием с местными и региональными органами власти [13].

Соответственно, со стороны региональных властей необходима организационная помощь субсидированным кинотеатрам, координация их деятельности, разработка и реализация программ по дальнейшему 
развитию кинопоказа в регионе. Поддержка может быть самой разной: от предложения концептуальных или точечных решений до создания стратегического плана комплексного развития кинопоказа в регионе.

Для методологической поддержки региональных органов власти по созданию программы развития кинопоказа в регионе может быть привлечен Проектный офис Министерства культуры - ФГБУК «Роскультпроект», наделенный, в том числе, полномочиями для решения задач по разработке рекомендаций по повышению эффективности управленческих решений в сфере культуры.

В целях постоянного мониторинга, оценки и оперативного взаимодействия в регионе должно быть реализовано техническое решение информационного обмена путем создания информационной системы или модернизации действующей. Существование единой региональной информационной системы позволит решить вопросы оперативной информации и, соответственно, оперативной помощи и поддержки.

Важной задачей является и наличие в системе регионального кинопоказа управленческих кадров, способных работать в соответствии с современными условиями. Площадками для проведения мероприятий по созданию компетенций работников субсидированных кинотеатров (организации мастер-классов, круглых столов с целью получения практического опыта) могут стать региональные центры, создаваемые в рамках «Программы создания центров культурного развития», реализуемой Министерством культуры совместно с органами исполнительной власти субъектов РФ [1].

Организация двухуровневой системы дальнейшей поддержки деятельности субсидированных кинотеатров позволит сформировать устойчивую связь между программами федерального и регионального уровня.

Государственная поддержка киноиндустрии путем прямой финансовой помощи кинотеатрам является важным инструментом развития кинопоказа в регионах России, повышения доступности современного кинопоказа, увеличения доли российского кино в прокате. Одновременно этот проект решает вопросы не только привлечения зрителей к российскому кино, но и задачи создания нового бизнеса на территории, новых рабочих мест, центров просвещения и досуга.

В то же время необходимо констатировать, что в полной мере задачи по развитию кинопоказа на региональном уровне не могут быть решены только путем федерального субсидирования. Необходим дальнейший диалог и совместная работа государственных органов (Министерства культуры, Фонда кино, региональных органов власти) в целях повышения эффективности бюджетных расходов и решения ключевых задач развития регионального кинопоказа.

\section{Библиографический список}

1. Распоряжение Правительства РФ «Программа создания центров культурного развития в малых городах и сельской местности» № 2716-р от 26.12.2014 г. (ред. от 30.11.2018 г.) [Электронный ресурс]. - Режим доступа: http://www.garant. ru/products/ipo/prime/doc/70737328/ (дата обращения: 02.03.2019).

2. Государственный доклад «О состоянии культуры в Российской Федерации в 2015 году» [Электронный ресурс]. - Режим доступа: http://www.mkrf.ru/activities/reports/report2015/ (дата обращения: 01.03.2019).

3. Государственный доклад «О состоянии культуры в Российской Федерации в 2017 году» [Электронный ресурс]. - Режим доступа: http://www.mkrf.ru/activities/reports/report2017/ (дата обращения: 01.03.2019).

4. Приказ Федерального фонда социальной и экономической поддержки отечественной кинематографии «Об утверждении получателей средств в целях создания условий для показа национальных фильмов в населенных пунктах Российской Федерации с численностью населения до 100 тыс. человек» № 171 от 25.12.2015 г. [Электронный ресурс]. - Режим доступа: http://www.fond-kino.ru/documents/official/ (дата обращения: 03.03.2019).

5. Приказ Федерального фонда социальной и экономической поддержки отечественной кинематографии «Об утверждении получателей средств в целях создания условий для показа национальных фильмов в населенных пунктах Российской Федерации с численностью населения до 100 тыс. человек» № 62 от 28.06.2016 г. [Электронный ресурс]. - Режим доступа: http://www.fond-kino.ru/documents/official/ (дата обращения: 03.03.2019).

6. Приказ Федерального фонда социальной и экономической поддержки отечественной кинематографии «Об утверждении получателей средств в целях создания условий для показа национальных фильмов в населенных пунктах Российской Федерации с численностью населения до 500 тыс. человек» № 115 от 19.12.2016 г. [Электронный ресурс]. - Режим доступа: http://www.fond-kino.ru/documents/official/ (дата обращения: 03.03.2019). 
7. Приказ Федерального фонда социальной и экономической поддержки отечественной кинематографии «Об утверждении получателей средств в целях создания условий для показа национальных фильмов в населенных пунктах Российской Федерации с численностью населения до 500 тыс. человек» № 162 от 20.11.2017 г. [Электронный ресурс]. - Режим доступа: http://www.fond-kino.ru/documents/official/ (дата обращения: 03.03.2019).

8. Приказ Федерального фонда социальной и экономической поддержки отечественной кинематографии «Об утверждении получателей средств в целях создания условий для показа национальных фильмов в населенных пунктах Российской Федерации с численностью населения до 500 тыс. человек» № 19 от 30.03.2018 г. [Электронный ресурс]. - Режим доступа: http://www.fond-kino.ru/documents/official/ (дата обращения: 03.03.2019).

9. Ивонинский, А. Н. Характеристика основных проблем предприятий кинопоказа в Российской Федерации // Проблемы современной экономики. - 2014. - № 1(49). - С. 238-240.

10. Колобова, Е. Ю. Установление состава факторов влияния на конкурентоспособность организаций кинопоказа // Инновационная наука. - 2016. - № 11-1. - С. 76-82.

11. Колобова, Е. Ю. Формирование системы управления конкурентоспособностью хозяйствующих субьектов кинопоказа // Петербургский экономический журнал. - 2017. - № 2. - С. 155-164.

12. Морщагина, Н. А. Особенности функционирования, тенденции и перспективы развития сетей кинотеатров в современных условиях / Н. А. Морщагина, Д. С. Скорчеллетти // Петербургский экономический журнал. - 2014. - № 1. - С. 119-126.

13. Сапелко, С. Н. Развитие унитарных предприятий кинопоказа как одно из приоритетных направлений совершенствования социально-культурного обслуживания населения / С. Н. Сапелко, Е. В. Сальникова // Петербургский экономический журнал. - 2016. - № 2. - С. 56-61.

14. Официальный портал Правительства Ростовской области [Электронный pecypc]. - Режим доступа: http://www.donland. ru/ (дата обращения: 04.03.2019).

15. Официальный сайт Федеральной службы государственной статистики (Росстат) [Электронный ресурс]. - Режим доступа: http://www.gks.ru/ (дата обращения: 03.03.2019).

16. Официальный сайт Федерального фонда социальной и экономической поддержки отечественной кинематографии [Электронный ресурс]. - Режим доступа: http://www.fond-kino.ru/ (дата обращения: 04.03.2019).

\section{References}

1. Rasporyazhenie Pravitel'stva RF «Programma sozdaniya tsentrov kul'turnogo razvitiya v malykh gorodakh i sel'skoi mestnosti» № 2716-r ot 26.12.2014 g. (red. ot 30.11.2018 g.) [Order of the Russian Federation Government «Program of creation of cultural development centers in small towns and rural areas» № 2716-p dated December 26, 2014 (ed. on November 30, 2018]. Available at: http://www.garant.ru/products/ipo/prime/doc/70737328/ (accessed 02.03.2019).

2. Gosudarstvennyi doklad «O sostoyanii kul’tury v Rossiiskoi Federatsii v 2015 godu» [State report «On the condition of culture in the Russian Federation in 2015»]. Available at: http://www.mkrf.ru/activities/reports/report2015/ (accessed 01.03.2019).

3. Gosudarstvennyi doklad «O sostoyanii kul'tury v Rossiiskoi Federatsii v 2017 godu» [State report «On the state of culture in the Russian Federation in 2017»]. Available at: http://www.mkrf.ru/activities/reports/report2017/ (accessed 01.03.2019).

4. Prikaz Federal'nogo fonda sotsial'noi i ekonomicheskoi podderzhki otechestvennoi kinematografii «Ob utverzhdenii poluchatelei sredstv v tselyakh sozdaniya uslovii dlya pokaza natsional'nykh fil'mov v naselennykh punktakh Rossiikoi Federatsii s chislennost’yu naseleniya do 100 tys. chelovek» № 171 ot 25.12.2015 g. [Order of the Federal Fund for social and economic support of national cinematography "On approval of recipients of funds in order to create conditions for the display of national films in settlements of the Russian Federation with a population of up to 100 thousand people» № 171 dated December 25, 2015]. Available at: http://www.fond-kino.ru/documents/official/ (accessed 03.03.2019).

5. Prikaz Federal'nogo fonda sotsial'noi i ekonomicheskoii podderzhki otechestvennoi kinematografii «Ob utverzhdenii poluchatelei sredstv v tselyakh sozdaniya uslovii dlya pokaza natsional'nykh fil'mov v naselennykh punktakh Rossiiskoi Federatsii s chislennost'yu naseleniya do 100 tys. chelovek» № 62 ot 28.06.2016 g. [Order of the Federal Fund for social and economic support of national cinematography "On approval of recipients of funds in order to create conditions for the display of national films in settlements of the Russian Federation with a population of up to 100 thousand people» № 62 dated June 28, 2016]. Available at: http://www.fond-kino.ru/documents/official/ (accessed 03.03.2019).

6. Prikaz Federal'nogo fonda sotsial'noi i ekonomicheskoi podderzhki otechestvennoi kinematografii «Ob utverzhdenii poluchatelei sredstv v tselyakh sozdaniya uslovii dlya pokaza natsional'nykh fil'mov v naselennykh punktakh rossiiskoi Federatsii s chislennost'yu naseleniya do 500 tys. chelovek» № 115 ot 19.12.2016 g. [Order of the Federal Fund for social and economic 
support of national cinematography «On approval of recipients of funds in order to create conditions for the display of national films in settlements of the Russian Federation with a population of up to 500 thousand people» № 115 dated December 19, 2016]. Available at: http://www.fond-kino.ru/documents/official/ (accessed 03.03.2019).

7. Prikaz Federal'nogo fonda sotsial'noi i ekonomicheskoi podderzhki otechestvennoi kinematografii «Ob utverzhdenii poluchatelei sredstv v tselyah sozdaniya uslovii dlya pokaza natsional'nykh fil'mov v naselennykh punktakh Rossiiskoi Federatsii s chislennost’yu naseleniya do 500 tys. chelovek» № 162 ot 20.11.2017 g. [Order of the Federal Fund for social and economic support of national cinematography "On approval of recipients of funds in order to create conditions for the display of national films in settlements of the Russian Federation with a population of up to 500 thousand people» № 162 dated November 20, 2017]. Available at: http://www.fond-kino.ru/documents/official/ (accessed 03.03.2019).

8. Prikaz Federal'nogo fonda sotsial'noi i ekonomicheskoi podderzhki otechestvennoi kinematografii «Ob utverzhdenii poluchatelei sredstv v tselyakh sozdaniya uslovii dlya pokaza natsional'nykh fil'mov v naselennykh punktakh Rossiiskoi Federatsii s chislennost'yu naseleniya do 500 tys. chelovek» № 19 ot 30.03.2018 g. [Order of the Federal Fund for social and economic support of national cinematography «On approval of recipients of funds in order to create conditions for the display of national films in settlements of the Russian Federation with a population of up to 500 thousand people» № 19 dated March 30, 2018]. Available at: http://www.fond-kino.ru/documents/official/ (accessed 03.03.2019).

9. Ivoninskii A. N. Kharakteristika osnovnykh problem predpriyatii kinopokaza v Rossiiskoi Federatsii [Characteristics of the main problems of enterprises of film exhibition in the Russian Federation]. Problemy sovremennoi ekonomiki [Problems of modern economy], 2014, I. 1(49), pp. 238-240.

10. Kolobova E. Ju. Ustanovlenie sostava faktorov vliyaniya na konkurentosposobnost' organizatsii kinopokaza [Establishment of composition factors of influence on competitiveness of the organizations of the cinema]. Innovatsionnaya nauka [Innovative science], 2016, I. 11-1, pp. 76-82.

11. Kolobova E. Ju. Formirovanie sistemy upravleniya konkurentnosposobnost'yu khozyaistvuyushchikh sub'ektov kinopokaza [Formation of competitiveness management system of film screening economic subjects]. Peterburgskii ekonomicheskii zhurnal [St. Petersburg economic journal], 2017, I. 2, pp. 155-164.

12. Morshchagina N. A., Skorchelletti D. S. Osobennosti funktsionirovaniya, tendentsii i perspektivy razvitiya setei kinoteatrov $\mathrm{v}$ sovremennykh usloviyakh [Features of functioning, trends and prospects of development of cinema networks in modern conditions]. Peterburgskii ekonomicheskii zhurnal [St. Petersburg economic journal], 2014, I. 1, pp. 119-126.

13. Sapelko S. N., Sal'nikova E. V. Razvitie unitarnykh predpriyatii kinopokaza kak odno iz prioritetnykh napravlenii sovershenstvovaniya sotsial'no-kul'turnogo obsluzhivaniya naseleniya [Development of unitary enterprises of film screening as one of the priority directions of improvement of social and cultural service of the population]. Peterburgskii ekonomicheskii zhurnal [St. Petersburg economic journal], 2016, I. 2, pp. 56-61.

14. Ofitsial'nyi portal Pravitel'stva Rostovskoi oblasti [Official portal Of the government of the Rostov region]. Available at: http:// www.donland.ru/ (accessed 04.03.2019).

15. Ofitsial'nyi sait Federal'noi sluzhby gosudarstvennoi statistiki (Rosstat) [Official website of the Federal state statistics service (Rosstat)]. Available at: http://www.gks.ru/ (accessed 03.03.2019).

16. Ofitsial'nyi sait Federal'nogo fonda sotsial'noi i ekonomicheskoi podderzhki otechestvennoi kinematografii [Official website of the Federal Fund for social and economic support of Russian cinema]. Available at: http://www.fond-kino.ru/ (accessed 04.03.2019). 